\title{
Pela reconstrução dos mitos da enfermagem a partir da qualidade emancipatória do cuidado
}

\author{
RECONSTRUCTING MYTHS OF NURSING THROUGH THE EMANCIPATORY QUALITY OF CARE \\ POR LA CONSTRUCCIÓN DE LOS MITOS DE LAENFERMERÍA A PARTIR DE LA CUALIDAD \\ EMANCIPATÓRIADEL CUIDADO
}

\section{Maria Raquel Gomes Maia Pires'}

\section{RESUMO}

Esse estudo teórico se debruça sobre a influencia dos mitos e tradições históricas da enfermagem na prática profissional, presentes em muitos dos seus agentes, à luz triedro emancipatório do cuidar, expresso pelo conhecer para cuidar melhor, cuidar para confrontar, cuidar para emancipar. Remete-se ao estudo da fragilidade política do enfermeiro para desvelar aspectos conservadores e positivistas recorrentes na profissão, fruto da historicidade que a constrói. Objetiva-se refletir teoricamente sobre os discursos conservadores da enfermagem e indicar, com base na perspectiva emancipatória do cuidar, possibilidades para reconstrução do fazer histórico da categoria, ampliando as dimensões da prática social. Propõese que a enfermagem assuma os mitos e ritos como ricas contradições da realidade, desmitificando-os reflexivamente por meio da politicidade do cuidado (mediação entre ajuda e poder capaz de forjar autonomias).

\section{DESCRITORES}

Educação em enfermagem. História da enfermagem. Papel do profissional de enfermagem.

\section{ABSTRACT}

This theoretical study focuses on the influence of myths and historical traditions of Nursing in professional practice, and is based on the emancipatory trihedron of care: to know in order to better care, to care in order to confront, to care in order to emancipate. The analysis of nurses' political fragility unveiled conservative and positivist tendencies that have been historically associated with the profession, leading to a theoretical reflection on conservative discourses about Nursing. Through the emancipatory care perspective, the study aims at pointing out possibilities for the reconstruction of historical practices of health care, adding dimension to social practices. Additionally, Nursing should take these myths and rituals as rich contradictions of reality, reflexively demystifying them through the politics of care (mediation between help and power to create autonomy).
\end{abstract}

\section{KEY WORDS}

Education, nursing. History of nursing. Nurse's role.

\section{RESUMEN}

Ese estudio teórico se inclina sobre la influencia de los mitos y tradiciones históricas de la enfermería en la práctica profesional, presentes en muchos de sus agentes, a la luz triedro emancipado del cuidar, expreso por el conocer para cuidar mejor, cuidar para confrontar, cuidar para emancipar. Se remete al estudio de la fragilidad política del enfermero para desvelar aspectos conservadores y positivistas recurrentes en la profesión, fruto de la historicidad que la construye. Se objetiva reflejar teóricamente sobre los discursos conservadores de la enfermería e indicar, con base en la perspectiva emancipada del cuidar, posibilidades para la reconstrucción del hacer de la categoría, ampliando las dimensiones de la práctica social. Se propone que la enfermería asuma los mitos y ritos como ricas contradicciones de la realidad, los desmitificando reflexivamente por medio de la politicidade del cuidado (mediación entre ayuda y poder capaz de forjar autonomías).

\section{DESCRIPTORES}

Educación en enfermería. História de la enfermería. Rol de la enfermera.

\author{
Enfermeira. Mestre \\ e Doutora em Polí- \\ tica Social pela Uni- \\ versidade de Brasí- \\ lia. Professora \\ Adjunta da Escola \\ de Enfermagem, \\ Universidade \\ Federal de Minas \\ Gerais (UFMG), Belo \\ Horizonte, MG, Brasil. \\ raquelgmp@ \\ enf.ufmg.br
}




\section{INTRODUÇÃO}

A enfermagem é uma prática social complexa e contraditória, permeada por mitos históricos que compõem o universo de símbolos e o imaginário que se tem da profissão. A exemplo disso, os estereótipos da enfermeira santa (religiosa), presente em muitos filmes, convivem com a imagem sexualizada da profissão (prostituta), muito comum, ainda, em grande parte dos materiais produzidos pela indústria pornô. A forma com que se tem lidado essa visão equivocada da profissão ampara-se na negação sistemática desse componente intrínseco ao desenvolvimento da enfermagem moderna. Calcada na historicidade que a constrói ${ }^{(1-3)}$, a enfermagem tem procurado sistematicamente apagar as imagens sacralizadas ou pecadoras da profissão por meio de um cientificismo pouco crítico, calcado no tecnicismo e na exacerbação da face formal do conhecimento (instrumentalidade técnica), em detrimento da face política que lhe complementa (intervenção, ética) ${ }^{(4)}$. Nestes termos, tem-se defendido um modelo de profissional assexuado, rí-gido, autoritário, excessivamente técnico e pouco politizado. Tal perfil ideologizado, além de dificultar a capacidade de intervenção crítica dos sujeitos, tem contribuído para a reprodução de um modelo de atenção à saúde curativo e hospitalocêntrico $^{(5)}$, não conseguindo reconstruir os mitos e discursos con-servadores da profissão, que permanecem latentes no imaginário e idéias preconcebidas que a sociedade tem da enfermagem.

Esse artigo, um estudo teórico, propõe uma nova forma de lidar com os mitos e discursos da profissão, menos assente no mascaramento da realidade, mais próxima à afirmação das contradições históricas como pressuposto para superação e reconstrução de práticas e realidades. Acredita-se que, da mesma forma que é preciso transcender a primazia da qualidade formal do enfermeiro, articulando-a dialeticamente à qualidade política ${ }^{(4)}$, os mitos $\mathrm{e}$ estereótipos (como por exemplo as imagens santas e impuras da profissão) precisam ser(re)assu-midas como parte da história, que tanto conforma como é capaz de re-inventar realidades, pelo mesmo movimento político e inquieto inerente ao à dialética histórico-estrutural ${ }^{(6)}$. Na primeira parte do texto faz-se breve discussão sobre qualidade política e triedro emancipatório do cuidar, constructos centrais para o estudo. Em seguida, e com base nessas concepções, faz-se analise dos perfis do enfermeiro com fragilidade e qualidade política ${ }^{(4)}$, onde se identificam as heranças históricas da profissão. Por fim, propõe-se algumas indicações, amparadas no triedro emancipatório do cuidar, que podem subsidiar a (re)construção dos mitos e prática da profissão, ampliando conquistas históricas.

\section{Digressões sobre os constructos da análise: qualidade política e triedro emancipatório do cuidar}

A concepção de qualidade, enquanto capacidade de intervenção humana, inscreve-se no plano subjetivo das relações sociais de contextos sócio-históricos, reconstruindose no cotidiano. A idéia de contexto se expressa pela provisória delimitação de tempo, espaço e produção de idéias compartilhadas por atores sociais diversos. Pode-se dizer que a qualidade tem duas faces, formal e política, dialeticamente complementares do fenômeno processual que faz parte. A qualidade formal constitui condição essencial para que a qualidade política se expresse enquanto atitude de intervenção no cotidiano, conferindo significado histórico aos saberes e atos da humanidade. Qualidade formal e política constituem um todo indissociável, totalidade histórica superável pelos rumos da dialética ${ }^{(7-10)}$.

A qualidade formal é tão necessária à ação humana quanto sua dimensão política. De fato, pensar dialeticamente uma realidade é entender que a forma, a técnica, o conteú-do, jamais podem vir dissociados de sua dimensão ética. De nada vale o exímio especialista que não é capaz de perceber os conflitos, ideologias e contradições existentes na prática social. Num exemplo extremo, um cientista nuclear, capaz de construir bombas atômicas cada vez mais sofisticadas e poderosas, deve também saber se posicionar sobre seu uso. Nessa discussão, é a dimensão política do conhecimento que realmente importa. A capacidade de mudar, crescer e apreender ao longo dos tempos está diretamente relacionada ao processo da criatividade como dimensão humana. A elaboração do pensamento em favor da criação, construção, abstração e recriação de realidades é traço próprio do fazer humano, permeado de qualidade política.

Conforme se observa na literatura ${ }^{(11)}$, pior que a pobreza material é a pobreza política de não perceber porque se é pobre. A passividade e submissão presentes na fragilidade política contribuem para usurpar possibilidades criativas de existência. Não se pretende usurpar a ambigüidade dialética presente nos fenômenos e relações sociais, mas resignificálos enquanto variáveis que se interpenetram no contexto histórico. Se mensurar a pobreza material é procedimento complexo e relativo (e válido), que dirá abordar sua dimensão política. Ao desenvolver o conceito de pobreza políti$c a$, o autor acrescenta o aspecto de incapacidade de autogestão humana de um povo incapaz de criar seu próprio projeto de desenvolvimento ${ }^{(11)}$. A historicidade capaz de gerir e influir sobre o destino diferencia as sociedades em termos de qualidade política. Quanto mais consciente do papel de ator social que se pode conquistar, mais próximos da emancipação, construtora e recriadora de cotidianos mais dignos. Não se pretende mitificar ou romantizar o caráter 
árduo dos enfrentamentos históricos e da mobilização popular para se minimizar as injustiças sociais, inclusive a econômica. Sabe-se também que condicionantes sócio-econômicos, como moradia, saúde, expectativa de vida, educação, renda e acesso a bens de consumo, determinam sobremaneira a pobreza material como obstáculo à cidadania crítica, atuante, participativa, criativa. O caráter estrutural das desigualdades, enquanto marca registrada das sociedades, acentua eternos contrários superáveis dialeticamente nos enfrentamentos cotidianos. Não que seja simples ou banal tal emancipação, pois envolve luta política, capacidade organizativa, conhecimento, autonomia econômica e níveis elaborados de participação social. Perceber que as sociedades serão eternamente diferentes, ambíguas, desiguais, plurais e, por isso mesmo, reconstruíveis, constitui detalhe importante à qualidade política dos sujeitos. Tal premissa se torna possível quando arraigada de conquista histórica. Não é processo fácil, sequer único, apenas possível e incompleto, requerendo esforço coletivo para recriação de cotidianos. Trata-se de entender qualidade política como participação crítica em cenários históricos, podendo contribuir para a redução das desigualdades sociais em saúde.

A qualidade política torna historicamente relevantes os processos participativos, redimensionando poderes em relações de autoridade partilhada. Participar significa democratizar poderes, repolitizando práticas sociais em seus múltiplos espaços ${ }^{(12)}$. Poder de decidir, de elaborar projetos próprios de desenvolvimento, de argumentar, de ter acesso às garantias de uma vida digna. Em uma frase: qualidade política é a possibilidade as pessoas têm de conquistar autonomia (entendendo-a relativa, processual, relacional, síntese de muitas ajudas $)^{(13)}$, reconstruindo história, intervindo criativamente no cotidiano pela participação. A exigência que a qualidade tem de si mesma, na perspectiva dialética de se superar, requer disciplina e rigor em todas as fases de seu processo de constante vir-a-ser.

Nesses termos, a qualidade formal (técnica, instrumental) é tão importante para o desenvolvimento da enfermagem quanto a face política (ética, participação, negociação, democratização de poderes) que a complementa, em contextos sócio-históricos específicos ${ }^{(4)}$. O conhecimento excessivamente técnico, sendo poder, conquista espaços e garante certa autonomia, embora restrita e submetida a poderes e macroestruturas conjunturais. Ou seja, saber avaliar a condição clínica da pessoa, elaborar diagnósticos de enfermagem e traçar planos de cuidados assegura certo espaço profissional ao enfermeiro, porém não rompe com a lógica estrutural e o modelo de atenção centrado no hospital e na doença, por exemplo. Para além da qualidade técnica da assistência prestada, que privilegia um cuidado instrumental com menos riscos de imperícia, há de se buscar maior qualidade política, acentuando a politicidade (disrupção, provisoriedade, subversão) do cuidar, capaz de emancipar pela mesma ajuda que mantém relações de poderes, partilhando assimetrias. A título de breve adendo, pode-se dizer que politicidade do cuidado ${ }^{(6)}$, em sentido ecológico, social, polí- tico, epistemológico e emancipatório, vai além de assistir com qualidade técnica livre de dados. Significa inaugurar novas formas de mediar relações de ajuda-poder capazes de romper sistemeticamente com estruturas de dominação desigualmente injustas, democratizando espaços de poder e ampliando autonomia não só de quem detém maiores poderes institucionais para cuidar (profissional de saúde), mas igualmente de quem está (em sentido transitório e relacional) sendo cuidado (usuário, família, comunidade). Nesse sentido, e entendendo que o conhecimento constitui uma forma de saber cuidar ${ }^{(14)}$ adentra-se na necessidade de se refletir sobre a epistemologia crítica do cuidado, expresso nesse estudo pelo que se vem chamando triedro emancipatório do cuidar ${ }^{(15-16)}$.

\section{Triedro emancipatório do cuidar: conhecer para cuidar melhor, cuidar para confrontar, cuidar para emancipar}

A politicidade do cuidado está calcada na reconstrução da autonomia de sujeitos por meio da gestão da ajuda-poder. Essa concepção se fundamenta pelo que se denomina triedro emancipatório do cuidar: conhecer para cuidar melhor, cuidar para confrontar, cuidar para emancipar (a escolha da metáfora do triedro, meramente ilustrativa, foi inspirada no fato dessa figura geométrica ser formada constitucionalmente por três faces integradas, visualizadas em conjunto e gerando diversas imagens a depender da posição e incidência do jogo de luz e sombras possíveis). Com tal proposição, argumenta-se em favor do conhecimento como forma natural de participar de um mundo socialmente fundado em relações de ajuda-poder. Articulando saber e poder, ou reconhecendo que o cuidado é também uma forma de conhecimento capaz de forjar possibilidades libertárias, amplia-se a capacidade de confronto e re-ordenamento das assimetrias de poder, emancipando por meio da mesma ajuda que domina e subjulga. Desconstruir progressivamente relações de domínios por meio de ações solidárias implica um resgate crítico da discussão sobre conhecimento e poder, que sempre foi tensa e dialética. Sobre tal questão, defende-se a idéia de que o conhecimento tem uma vocação emancipatória ${ }^{(17)}$, onde quanto mais se conhece e se compreende, mais se é capaz de, reconhecendo os limites do 'verdadeiro', dedicar-se à sua procura e, por meio desse processo incessante de busca, emancipar-se relativamente de certas concepções. Diante do desafio da complexidade do real, urge ao conhecimento refletir-se sobre si mesmo, situando-se e problematizando-se no exercício processual de aproximar-se da realidade.

Para se cuidar uns dos outros, numa propulsão tanto criativa quanto dominadora, incorpora-se, apreende-se e interpreta-se a realidade, buscando-se qualidade política nas distintas formas de (re)inventá-la. Nesse espírito ampliado, entenda-se conhecimento como dinâmica viva de produzir interpretações, significados, críticas e formas de participar da realidade. Conhecer é reconstruir possibilidades de conviver, atuar e interagir com o planeta, concebendo a disrupção, o confronto e a provisoriedade como cerne. É a maneira como a natureza se mantém diversa, única e incapturável, reconduzindo tem- 
pos, espaços e histórias de forma não-linear e irredutível. Precisa-se, então, conhecer para cuidar melhor, cuidar para confrontar, cuidar para emancipar, porque tal politicidade se expressa na intrínseca habilidade de cognição presente na natureza, na cultura e na história da humanidade ${ }^{(15-16)}$.

As pessoas são seres de cuidado e de destruição, de ajuda e de coerção, exprimem-se pela tensa disputa da loucura e sapiência que as encerra ${ }^{(13)}$. $\mathrm{O}$ ato de cuidar, portanto, sofre pressões tanto da racionalidade empírica-prático-instrumental, como das pulsões incontroláveis e delinqüentes que integram o homo sapiens-demens. O cuidado é uma mediação criadora entre a racionalidade e a pulsão presente no afeto. Misto de estratégia, ruptura e submissão, o cuidado transita entre a humanidade sapiens e demens, unindoas numa propulsão reorganizadora de poderes conformados. A politicidade do cuidado contempla o potencial da mudança, da desconstrução reconstrutiva, da ruptura dos interditos e sublevações opressivas, tendo por foco a construção da autonomia, síntese de diversos modos de cuidar. Trata-se de uma autonomia dependente $e^{(13)}$ porque não existe autonomia viva que não seja dependente (do meio, da auto-organização, da energia vital, da cultura, da história, da família, da sociedade, do Estado) ou polidependente. A liberdade do sujeito autônomo ocorreria numa situação que comporte, ao mesmo tempo, ordem e desordem, estabilidade e regularidade, certezas a priori para que seja possível escolher e decidir num mínimo de desordem e risco. A autonomia do indivíduo humano se funda na qualidade de sujeito que se auto-afirma ocupando o centro do seu mundo, mas que comporta um Nós (família, espécie, sociedade), uma inscrição comunitária (família, pátria), hereditária, histórica e cultural.
A politicidade do cuidado medeia o confronto das tensões entre razão e demência presente nos sujeitos, podendo inaugurar novas ordenações de poderes. Trata-se de argumentar em prol de uma nova lógica do cuidar, onde se exercite uma ajuda que, sendo poder, tanto subjulga, como é capaz de libertar. Significa desenvolver uma epistemologia dialética do cuidado que ganhe em intensidade subversiva, mesmo sendo relação de dominação. O cuidado aqui proposto contempla toda a ambigüidade e complexidade do sujeito, fundamentando-se eticamente na libertação ${ }^{(18)}$. A gestão a ajuda-poder para a emancipação de sujeitos envolve conhecer para cuidar melhor, cuidar para confrontar, cuidar para emancipar, porque precisa-se entender mais profunda e dialeticamente a realidade complexa para nela agir e cuidar, em nome de uma ética mais justa, cuidadora, igualitária e libertadora ${ }^{(18)}$. Ajudando para que os sujeitos conheçam melhor, unindo forma e conteúdo, quantidade e qualidade (formal e política), razão e afeto, as chances e conquistas cidadãs podem ser alargadas. Tal intervenção cuidadora e subversiva, pode fortalecer autonomias e qualificar enfrentamentos, emancipando pela desconstrução progressiva de assimetrias de poder em contextos históricos.

\section{Sobre os mitos e conservadorismos da enfermagem e a necessidade de (re)construi-los}

Pela pertinência da discussão sobre qualidade política dos profissionais para a necessidade de (des)construir os mitos e conservadorismos da enfermagem, posto que envolve crítica ampliada de contexto sócio-histórico, refira-se o quadro abaixo como ilustração para o debate ${ }^{(4)}$, onde contam o delineamento das características dos enfermeiros mais próximos e distantes da qualidade política.

Quadro 1 - Características dos enfermeiros aproximativos e distanciados da qualidade política

\begin{tabular}{|c|c|}
\hline Enfermeiros próximos da qualidade política & Enfermeiros com fragilidades políticas \\
\hline 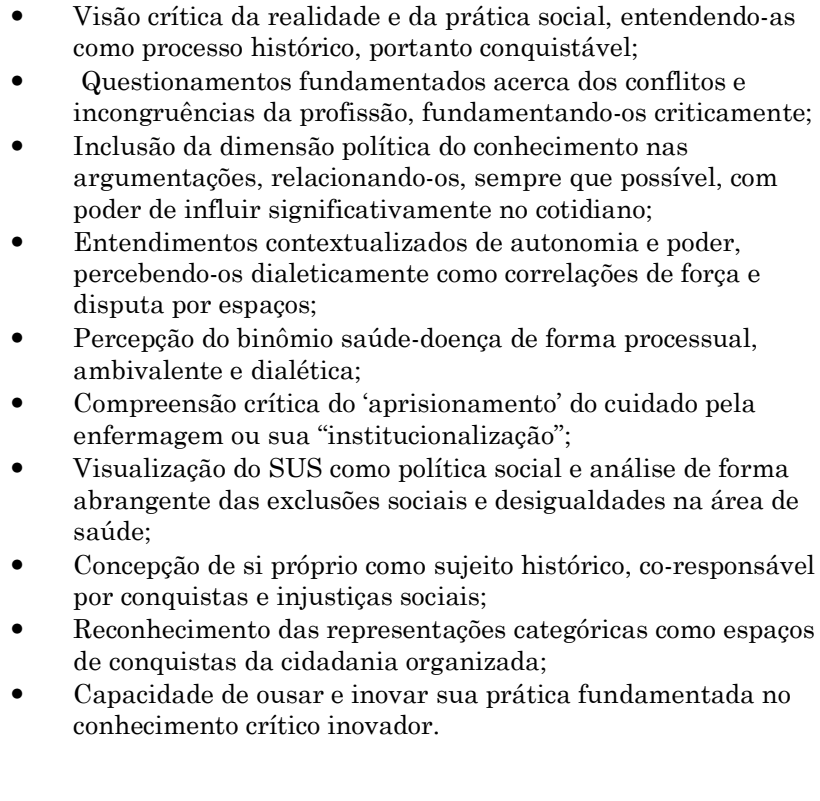 & $\begin{array}{l}\text { - Priorização da face formal do conhecimento em detrimento } \\
\text { da dimensão política que a complementa; } \\
\text { - Visão pouco crítica da prática social e linearidade na } \\
\text { interpretação dos conflitos inerentes à profissão; } \\
\text { - Fragilidade no entendimento do sujeito histórico, capaz de } \\
\text { trilhar oportunidades e cidadanias; } \\
\text { - Indícios de entendimento da saúde sob o enfoque } \\
\text { cartesiano, mecaniscista, tecnicista, normativo- } \\
\text { institucional, fragmentado; } \\
\text { Desconhecimento das representações da categoria } \\
\text { enquanto espaço de correlações de força e disputa por } \\
\text { espaços; } \\
\text { Re-edição, de forma pouco crítica, de tradições, valores e } \\
\text { discursos da instituição de saúde, contribuindo para } \\
\text { relações de poder pouco democráticas; } \\
\text { Dificuldades em realizar análise de conjuntura } \\
\text { relacionadas à desigualdade social em saúde (pouca } \\
\text { percepção do SUS enquanto política social); } \\
\text { Relação de autonomia como conquista individual atrelada } \\
\text { a proficiência técnica; } \\
\text { Tendência ao tecnicismo na prática profissional e certa } \\
\text { acomodação na busca por qualificações; } \\
\text { Visão restrita de cuidado à assistência, não percebendo a } \\
\text { multiplicidade do cuidar na enfermagem e nas relações } \\
\text { sociais como um todo. }\end{array}$ \\
\hline
\end{tabular}

Fonte: adaptado de Pires $^{(4)}$ 
Observa-se que os enfermeiros com características próximas à fragilidade política tendem a reproduzir os mitos $\mathrm{e}$ conservadorismos da profissão, com pouca análise do componente ideológico que mascara as contradições da prática social. Bem reparado, esse perfil mais conservador da enfermagem revela excentricidades e ambigüidades peculiares, próprias do imaginário que se tem da profissão, fundada na historicidade que lhe conforma. Se por um lado o quadro acima revela traços da fragilidade política do enfermeiro, por outro, o forte comprometimento com a excelência técnica e o tradicionalismo da profissão identifica-se com o discurso tecnicista da enfermagem, personificando a maioria dos mitos e ritos históricos ${ }^{(1-3)}$. Nesse particular, vale dizer que a opção radical pela qualificação e proficiência formal do conhecimento é capaz de ousar e inovar possibilidades, traduzindo-se em ganhos e conquistas para a área que, se não são capazes de transcender visões e práticas de saúde, expressam ambigüidades potencialmente transformadoras. Por revelar forte expressão de um modelo de profissão que procurou forjar, suplantar e mascarar os estereótipos históricos da profissão para se firmar no status quo, analise-se o caso de Florence Nightingale, precursora da enfermagem moderna.

Com as devidas proporcionalidades de tempo e espaços sócio-históricos, e longe de uma análise mais apurada, pode-se dizer que a fragilidade política do enfermeiro da contemporaneidade sofre influencia de forma muito peculiar da presença simbólica, cultural e imaginária do mito-fundador ${ }^{(21-22)}$ da profissão, Florence Nightingale. Como Florence, a enfermagem atual tende a defender o aprimoramento técnico da profissão associado à rígida disciplina, com alguns focos de resistências dignos de notas, expressos, dentre outros, pela participação da categoria nas discussões e implementações de mudanças curriculares na graduação e na política de saúde do Brasil. Recorde-se, ainda, as ambigüidades presentes na prática dessa notória aristocrata inglesa, Florence Nightingale, onde, ao mesmo tempo em que serviu aos interesses do governo inglês em guerra imperialista de forma obediente e disciplinada, enfrentou sérias restrições ao trabalho feminino no início do século, tendo contribuído historicamente, de certa forma, para os avanços do movimento de mulheres ${ }^{(21)}$. Igualmente controversa é a trajetória da enfermagem, onde a formação diversificada em outras áreas do saber, a participação em organizações representativas da classe e ganhos de espaços significativos na política de saúde (gestão e gerencia de projetos governamentais e/ou não-governamentais, consul-torias, atividades empreendedoras, dentre outros) convivem contraditoriamente com a primazia do conhecimento formal sobre o político, com valores arraigados de tradicionalismo nos discursos, além de fraca capacidade de analisar contextualmente a inserção da prática da enfermagem na política social ${ }^{(23)}$.
Dizer que a qualidade formal não garante certa autonomia é uma imprecisão grosseira. Pode-se mesmo dizer que, à exemplo de Florence e com as devidas contemporaneidades, a preocupação com o aperfeiçoamento técnico é tão importante quanto a potilização dos espaços em que a prática ocorre. Ou seja, cuidar, apesar de bem mais complexo, também é autocuidado, curativos, aperfeiçoamento de procedimentos e tecnologias para o bem-estar e conforto da pessoa assistida. Porém, se é possível afirmar que a qualidade formal conquista algum espaço de poder ao enfermeiro, igualmente se pode argumentar que tal autonomia ocorre mais para manter processos desiguais de dominação, inclusive sobre a própria enfermagem que permanece atrelada à lógica do modelo biomédico de atuar, que para desconstruir assimetrias de poder, emancipando de forma mais coletiva e equânime.O inegável avanço conquistado pela enfermagem com destacada qualificação formal é imprescindível ao desenvolvimento da profissão, porém não é suficiente para emancipar coletivamente pelo cuidado ${ }^{(16)}$ e contribuir com a redução das desigualdades sociais. Em uma síntese provisória, dir-se-ia que a qualidade formal da prática profissional, centrada na proficiência técnica, pode garantir algum espaço de autonomia individual e restrito ao enfermeiro, legitimante da lógica institucionalizada, dominante e excludente de atuar em saúde. Porém, é a face política da qualidade que questiona e desconstrói sistematicamente as assimetrias de poder, tornando-as mais democráticas e inclusivas, alargando coletivamente as chances e oportunidades cidadãs.

Mesmo sabendo da importância dos mitos para a conformação das instituições sociais, tendo em vista os estudos sobre análise organizacional inspirados em teorias freudianas ${ }^{(22)}$, os mitos-fundadores também precisam ser resignificados em seu imaginário motor, a fim de que possam permitir mudanças conjunturais. A relevância de Florence para a profissão continuará, ainda por muito, motivo de orgulho na enfermagem, tal como o ideal conservador de autonomia profissional ligada exclusivamente à dimensão técnica do conhecimento. Porém, a relação dialética entre qualidade formal e política, entre ajuda e poder presente no cuidado, traduzidos pelo exercício crítico e reflexivo da profissão em contextos sóciohistóricos, potencializa desconstruções mais significativas de dominações expressas por mitos rigidamente estruturados, conservadores e limitadores de práticas sociais transformadoras. As conquistas da qualidade formal, necessárias tanto à lógica de mercado quanto ao fortalecimento de cidadanias, trazem em seu bojo algum espaço de poder e autonomia ${ }^{(23)}$ para a enfermagem. Porém, a forma excessivamente técnica de conhecer e cuidar traduz a ausência de um compromisso mais coletivo com a desconstrução de práticas opressivas no setor saúde. Essa fragilidade política contribui para as desigualdades sociais, expressas pela hegemonia do modelo biomédico, pelo saber científico sobre as múltiplas formas de cuidar da saúde e pelo obtuso tecnicismo presente na prática dos profissionais de saúde. 


\section{PARA (NÃO) CONCLUIR}

Tudo isso para dizer que a enfermagem, a exemplo de outras profissões da saúde, tem contribuído com a legitimação de políticas sociais pouco democráticas, tornando ela própria refém desses processos excludentes. A inclusão da tecitura política da qualidade do cuidado, em tensão dialética e desejável com sua face formal, pode potencializar movimentos emancipatórios para a saúde e para a enfermagem. No entanto, há de se investir no exercício crítico-reflexivo para reconstruir práticas, mitos e conservadorismos, por meio do conhecimento inovador e da participação, politizando a prática profissional nos espaços em que se insere. Politizar espaços significa partilhar poderes pela intervenção crítica e criativa de sujeitos em contextos sóciohistóricos específicos, ampliando cidadanias e práticas sociais. De forma aproximada, poder-se-ia ainda dizer que a prática dos profissionais de saúde, e em especial do enfermeiro, forjada na concepção emancipatória do cuidar, pode contribuir para a construção da autonomia de sujeitos (sejam esses usuários, família, comunidade ou a própria equipe de saúde) de forma crítica e participativa. Para tanto, propõe-se algumas indicações capazes de ampliar a politicidade do cuidar da profissão:

QUADRO 2- Indicações para (re)construção da prática da enfermagem

\begin{tabular}{|c|c|}
\hline $\begin{array}{l}\text { TRIEDRO DO } \\
\text { CUIDAR }\end{array}$ & POSSIBILIDADES \\
\hline $\begin{array}{c}\text { Conhecer para Cuidar } \\
\text { Melhor }\end{array}$ & $\begin{array}{l}\text { - compreender o contexto sócio-histórico onde são geradas as relações de ajuda-poder na política de } \\
\text { saúde e na prática profissional. (visão ampliada sobre cuidado, numa visão ecológica, social, } \\
\text { ontológica e epistemiológica); } \\
\text {-valorizar os diversos saberes e valores da equipe de enfermagem como ricas possibilidades de } \\
\text { cuidar, buscando estratégias conjuntas para o enfrentamento de problemas; } \\
\text { - Assumir os mitos e ritos da enfermagem como amplas possibilidades (ou politicidades) do cuidar, } \\
\text { desmitificando-os reflexivamente por meio da qualidade formal e política do conhecimento; }\end{array}$ \\
\hline $\begin{array}{l}\text { Cuidar para } \\
\text { Confrontar }\end{array}$ & $\begin{array}{l}\text { - gerir correlações de forças que proporcionem controle democrático e reordenamento de poderes } \\
\text { (politização dos espaços de atuação do enfermeiro, partilhando poderes na tentativa de acumular } \\
\text { forças de reação aos processos de dominações excludentes; fortalecimento de autonomias individuais } \\
\text { e coletivas na equipe de saúde e em sua relação com o outro, coletivizando conhecimentos capazes de } \\
\text { democratizar assimetrias de poder) } \\
\text { - recriar vínculos e confrontos de poderes presentes nos gestos de cuidar com as pessoas, concebendo- } \\
\text { as como sujeitos históricos, ampliando a dimensão da prática social da enfermagem; }\end{array}$ \\
\hline $\begin{array}{l}\text { Cuidar para } \\
\text { Emancipar }\end{array}$ & $\begin{array}{l}\text { - realizar a gestão inteligente da ajuda-poder na micropolítica do trabalho em saúde, inserida em } \\
\text { contextos sócio-históricos ricos em correlações de forças, capaz de oportunizar cenários propícios à } \\
\text { desconstrução progressiva de assimetrias de poder (centrado na pessoa como sujeito do seu processo } \\
\text { saúde-doença, desenvolvendo tecnologias de cuidar capazes de ajudar na construção de projetos } \\
\text { próprios para melhoria e/ou recuperação da saúde } \\
\text {-politizar os espaços de atuação do enfermeiro (assistência, gestão e gerência, educação em saúde, } \\
\text { ensino e pesquisa, consultorias), partilhando poderes na tentativa de acumular forças de reação aos } \\
\text { processos de dominações; } \\
\text {-valorizar e resgatar as diversas culturas e formas simbólicas como substratos da pluralidade e } \\
\text { possibilidades emancipatórias da relação de cuidado estabelecida pela enfermagem. }\end{array}$ \\
\hline
\end{tabular}

Fonte: adaptado de Pires ${ }^{(15)}$

\section{REFERÊNCIAS}

1. Pires D. Hegemonia médica na saúde e na enfermagem. São Paulo: Cortez; 1989

2. Germano RM. Educação e ideologia da enfermagem no Brasil. São Paulo: Cortez; 1985.

3. Silva GB. Enfermagem profissional: análise crítica. São Paulo: Cortez; 1986.

4. Pires MRGM. Enfermeiro com qualidade formal e política: em busca de um novo perfil [dissertação]. Brasília: Programa de Pós-Graduação em Política Social, Universidade de Brasília; 2001.
5. Teixeira C, organizador. Promoção e vigilância da saúde. Salvador: Instituto de Saúde Coletiva/UFBA; 2002.

6. Pires MRGM. Politicidade do cuidado como referência emancipatória para a gestão de políticas de saúde: conhecer para cuidar melhor, cuidar para confrontar, cuidar para emancipar [tese]. Brasília: Departamento de Serviço Social, Universidade de Brasília; 2004.

7. Demo P. Metodologia do conhecimento científico. São Paulo: Atlas; 2000.

8. Minayo MCS. O desafio do conhecimento: pesquisa qualitativa em saúde. São Paulo: Hucitec; 1992. 
9. Konder L. O que é dialética. São Paulo: Brasiliense 1993.

10. Kosik K. Dialética do concreto. $2^{\mathrm{a}}$ ed. Rio de Janeiro: Paz e Terra; 1976.

11. Demo P. Pobreza política. 2a ed. São Paulo: Cortez; 1992.

12. Demo P. Participação é conquista: noções de política social participativa. $2^{a}$ ed. São Paulo: Cortez; 1993.

13. Morin E. Método 5: A humanidade da humanidade. Porto Alegre: Sulina; 2002.

14. Boff L. Saber cuidar: ética do humano. $3^{\mathrm{a}}$ ed. Petrópolis: Vozes; 1999.

15. Pires MRGM. Politicidade do cuidado e processo de trabalho em saúde: conhecer para cuidar melhor, cuidar para confrontar, cuidar para emancipar. Ciênc Saúde Coletiva. 2005;10(4):1025-35.

16.Pires MRGM. Politicidade do Cuidado como referência emancipatória para a enfermagem: conhecer para cuidar melhor, cuidar para confrontar, cuidar para emancipar. Rev Lat Am Enferm. 2005;13(5):729-36.
17. Morin E. Método 3: O conhecimento do conhecimento. Porto Alegre: Sulina; 1999.

18. Dussel E. Ética da libertação na idade da globalização e da exclusão. $2^{\mathrm{a}}$ ed. Petrópolis: Vozes; 2002.

19. Thompson JB. Ideologia e cultura moderna: teoria social crítica na era dos meios de comunicação de massa. Petrópolis: Vozes; 1995.

20. Orlandi EP. Análise de discurso: princípios e procedimentos. $3^{\mathrm{a}}$ ed. Campinas: Pontes; 2001.

21. Miranda CL. O parentesco imaginário. São Paulo: Cortez; 1994.

22. Enriquez E. A Organização em análise: a teoria Freudiana e a sua contribuição ao estudo das organizações. Petrópolis: Vozes; 1997.

23. Gomes AMT, Oliveira DC. Estudo da representação social da autonomia profissional em enfermagem. Rev Esc Enferm USP. 2005;39(2):145-53. 